\title{
Cytotoxic and apoptotic effects of different extracts of Moringa oleifera Lam on lymphoid and monocytoid cells
}

\author{
MARINA POTESTA ${ }^{1 *}$, ANTONELLA MINUTOLO $^{1 *}$, ANGELO GISMONDI $^{1}$, \\ LORENA CANUTI $^{1}$, MAURICE KENZO ${ }^{2}$, VALENTINA ROGLIA ${ }^{1}$, FEDERICO MACCHI ${ }^{1}$, \\ SANDRO GRELLI $^{3}$, ANTONELLA CANINI ${ }^{1}$, VITTORIO COLIZZI ${ }^{1}$ and CARLA MONTESANO ${ }^{1}$ \\ ${ }^{1}$ Department of Biology, University of Rome 'Tor Vergata', I-00133 Rome, Italy; \\ ${ }^{2}$ Faculty of Medicine and Pharmaceutical Sciences, University of Dschang, Dschang B.P. 96, Cameroon; \\ ${ }^{3}$ Department of Experimental Medicine and Surgery, University of Rome 'Tor Vergata', I-00133 Rome, Italy
}

Received August 30, 2018; Accepted January 8, 2019

DOI: $10.3892 /$ etm.2019.7544

\begin{abstract}
Moringa oleifera Lam. (MO) is one of the most well-known and widely distributed species of the Moringaceae family in African communities, and various preparations of $M$. oleifera are used for the treatment of several diseases. Due to the extensive worldwide use of MO products, and the use of $\mathrm{MO}$ aqueous extract in traditional African medicine, the aim of the present study was to investigate the anti-proliferative, cytotoxic and pro-apoptotic activities of different aqueous extracts from leaves and seeds of M. oleifera (MOE), which have been prepared using different protocols, in lymphoid and monocytoid cells. The results of the present study demonstrated the anti-proliferative and pro-apoptotic effects of the aqueous extracts obtained from M. oleifera leaves and seeds on tumour cells; however, not on peripheral blood mononuclear cells (PBMCs) from healthy donors. The pro-apoptotic effect of MO seed aqueous extract (MOE-S) was correlated with decreased B-cell lymphoma 2 (BCL2) and sirtuin-1 (SIRT1) protein expression, which are involved in apoptosis. Considering the
\end{abstract}

Correspondence to: Dr Carla Montesano, Department of Biology, University of Rome 'Tor Vergata', 1 Via della Ricerca Scientifica, I-00133 Rome, Italy

E-mail:montesano@uniroma2.it

${ }^{*}$ Contributed equally

Abbreviations: MOE, Moringa oleifera aqueous extracts; PBMCs, peripheral blood mononuclear cells; MOE-S, Moringa oleifera aqueous extract seeds; BCL2, B-cell lymphoma 2; SIRT1, sirtuin-1; MO, Moringa oleifera Lam; L, Leaves; S, seeds; FS, fresh seeds; FW, fresh weight; EC50, 50\% effective concentration 50; lethal dose; BrdU, Bromodeoxyuridine; mol- small RNA, Moringa oleifera small RNA; mol-miRs, Moringa oleifera seeds microRNAs; MOE-f, Moringa oleifera extract, frozen; MOE-b, Moringa oleifera extract boiled; PI, Propidium Iodide

Key words: plant microRNA, Moringa oleifera, cross-Kingdom, apoptosis effects of plant secondary metabolites on human cells and the role of plant microRNA in cross-kingdom interactions, the presence of secondary metabolites and microRNA in MOE was characterised. In conclusion, $M$. oleifera aqueous extracts appeared to be able to differentially regulate proliferation and apoptosis in healthy cells and cancer cells, and this ability could be associated with the microRNA present in the extracts. These results highlighted the possible use of MOE as an adjuvant in traditional cancer therapy.

\section{Introduction}

Moringa oleifera Lam. (MO) is one of the most well-known, widely distributed and cultivated species of the Moringaceae family (1), which is also known as a miracle tree.

MO-based preparations are scientifically documented as being anti-inflammatory, antihypertensive, antimicrobial, antioxidant, and antidiabetic (2-4). Other works have reported that MO improves hepatic and renal functions and regulates thyroid hormones, protecting against oxidative stress, inflammation, hepatic fibrosis, liver damage, hypercholesterolaemia and cancer $(5,6)$.

The majority of human populations have long used medicinal plants as their primary source of health care. Many of these medicinal plants may have the scientific evidences to be considered in general practice (7).

Recently, particular attention has been provided to study the effects on human health of natural substances present in Mediterranean diet and their bioactive compounds demonstrating anticancer, antioxidant, antimicrobial and antiviral properties of olive oil correlated with the activity of phenolic and polyphenolic compounds present in it (8-12).

Recently, scientific studies have demonstrated the existence of a so-called 'cross-kingdom interaction', which is mediated by exogenous miRNAs that are derived from plants: These, inside the host cell, serve to regulate the gene expression machinery (12-16).

Concerning the latter, MO dried leaf extracts have exhibited anti-proliferative and antineoplastic activities in human tumour cell lines through apoptotic pathways (17-19). Moreover, in vivo and in vitro studies conducted in rats and 
human peripheral blood mononuclear cells, respectively, have demonstrated that MO-extracts are not toxic (6). Since MO derivatives are used worldwide, both as food and as an alimentary supplement, various studies have been performed to assess the scientific bases underlying the biological effects of this plant species. In particular, MO bioactivities were mainly associated with the secondary metabolites of the plant, such as phenols, terpenes, and alkaloids $(6,20)$.

For centuries, MO has been widely used in African traditional medicine, in the form of aqueous infusions, to promote health and cure diseases (21). In several African communities, different parts of this plant, such as the leaves, fruits, flowers and seeds, are also used to fight malnutrition, especially among children and nursing mothers $(22,23)$. The general aim of this work was to study in depth the effects of MO extracts and their bioactive components on apoptosis processes.

According to this evidence, the main purpose of the present work was the evaluation of the effects of MO aqueous extracts, obtained as suggested by African recipes, on monocytoid (THP1) and lymphoid (Jurkat) tumour cell lines and peripheral blood mononuclear cells (PBMCs) from healthy donors.

In particular, the ability of MO to inhibit tumour cell growth was investigated through the study of different apoptotic cellular mechanisms such as the repression of $B$-cell lymphoma 2 (BCL2) mRNA translation. BCL2 is a crucial anti-apoptotic protein that is involved in the intrinsic pathway and the block of NAD-dependent deacetylase sirtuin-1 (SIRT1), which induces apoptosis via regulating p53 activity (12,24-26).

Recently it has been shown how vegetal miRNAs derived from olive drupes are able to regulate the expression of BCL2 and SIRT1 in human tumor cells (12), a characterization of the boiled aqueous extract from MO to evaluate the presence of miRNAs and their possible involvement in the regulation of pro-apoptotic mechanisms has been done.

\section{Materials and methods}

Plant material. Moringa oleifera Lam. leaves and seeds were collected from a Cameroonian plantation and sampled by a 'traditional healer'. Leaves (L) and seeds (S), dried in the sun, were collected from the same trees, and they were used in traditional African medicine preparations. Moreover, a non-conventional preparation was prepared using fresh seeds (FS).

Extract preparation. M. oleifera extracts (MOE) were prepared according to African traditional methods: L, S and FS were ground with a mortar and pestle and boiled for $15 \mathrm{~min}$ in bidistilled water. Other types of extracts were obtained from the same MO plant parts, but they were powdered, resuspended in bidistilled water and frozen for $24 \mathrm{~h}$ at $-80^{\circ} \mathrm{C}$. All extracts were centrifuged, and the supernatants were recovered, filtered $(0.22 \mu \mathrm{m})$ and stored at $-20^{\circ} \mathrm{C}$. The extracts obtained from the boiling and freezing procedures are, from now on, referred to as boiled and frozen extracts, respectively.

Cell cultures. Human Jurkat E6-1 lymphoid and THP1 monocytoid cell lines (American Type Culture Collection, Manassas, VA, USA) were grown in a suspension culture at a density of $7 \times 10^{5}$ cells $/ \mathrm{ml}$.
Human PBMCs were obtained from 17 healthy blood donors attending the local Blood Transfusion Unit of Policlinico 'Tor Vergata' in Rome. PBMCs were separated by density gradient from the buffy coat according to the Ficoll-Hypaque standard technique (Lonza, Morristown, NJ, USA) and were cultured at a density of $10^{6}$ cells $/ \mathrm{ml}$. Tumour cell lines, Jurkat and THP1, and PBMCs from healthy donors were cultured in Roswell Park Memorial Institute (RPMI) 1640 medium (Invitrogen; Thermo Fisher Scientific, Inc., Waltham, MA, USA) supplemented with $10 \%$ fetal bovine serum (FBS; Invitrogen; Thermo Fisher Scientific, Inc.), $2 \mathrm{mM}$ glutamine (HyClone; GE Healthcare Life Sciences, Logan, UT, USA), $50 \mathrm{U} / \mathrm{ml}$ penicillin and $50 \mathrm{U} / \mathrm{ml}$ streptomycin (HyClone; GE Healthcare Life Sciences). All cell lines and PBMCs were cultured at $37^{\circ} \mathrm{C}$ in a $5 \% \mathrm{CO}_{2}$ humidified atmosphere in the presence or absence of the various $\mathrm{MO}$ extracts (MOE) at different concentrations, which varied between 0.01 and $10 \mathrm{mg}$ of fresh plant weight equivalent (FW) per $\mathrm{ml}$ of culture medium, for $72 \mathrm{~h}$. The ethical approval for the collection and use of human samples was obtained in 2014, from ethical board of 'Tor Vergata' hospital, protocol number 15/14 (D.M.08.02.2013-D.G.R.146/2013; D.D.G.467 del 25.07.2013), all patients provided written informed consent.

Cell death/viability and proliferation assays. Amounts of viable and dead cells were assessed by the trypan blue (Euroclone S.p.A., Milan, Italy) exclusion test, and a negative (water) proliferation control was used. After $72 \mathrm{~h}$, viable and dead cells, treated and untreated, were calculated as a fold change with respect to untreated cells at Time 0 .

Calculation of EC50 and LD50. Cumulative results from at least three different measurements were used to calculate the MOE concentration required to reduce cell proliferation by $50 \%$ (EC50) or to induce death in 50\% of cells (LD50). EC50 and LD50 were evaluated in all cell lines and in PBMCs using sigmoidal dose-response regression curves, using GRAPH PAD PRISM software.

Intracellular BCL2 and SIRT1 staining. BCL2 and SIRT1 intracellular expression was evaluated by flow cytometry analysis. After 72 h, transfected cells were harvested, fixed and permeabilized with $70 \%$ ethanol and incubated with PE-conjugated anti-human BCL2 (BD Biosciences, Franklin Lakes, NJ, USA), rabbit anti-human SIRT1 (Santa Cruz Biotechnology, Inc., Dallas, TX, USA) and anti-rabbit IgG-PE antibodies (Calbiochem; Merck KGaA, Darmstadt, Germany). Stained cells were analysed using a CytoFLEX flow cytometer (Beckman Coulter, Inc., Brea, CA, USA) and CytExpert 1.2 software (Beckman Coulter, Inc.).

Apoptosis assays. After $72 \mathrm{~h}$ of incubation with MOE, apoptosis was evaluated by flow cytometry (CytoFLEX; Beckman Coulter, Inc.) assessment of hypodiploid events. Cells were harvested, washed twice in PBS and incubated for $20 \mathrm{~min}$ in $70 \% \mathrm{EtOH}$ at $-20^{\circ} \mathrm{C}$. After incubation, cells were washed and stained in propidium iodide $1.25 \mu \mathrm{g} / \mathrm{ml}$. Events were gated on forward vs. orthogonal scatter in such a way that degraded DNA from cell debris or from doublets was excluded and nuclei from viable, apoptotic and necrotic cells were 
assayed. Data acquisition and analyses were performed for 150,000 events for each sample and analysed using CytExpert 2.0 (Beckman Coulter, Inc.).

Bromodeoxyuridine proliferation assay. The percentage of DNA synthesis in the cells was detected by the bromodeoxyuridine (BrdU) In Situ Cell Proliferation kit (FLUOS, Roche), according to the manufacturer's instructions, and analysed using CytoFLEX (Beckman Coulter, Inc.).

HPLC-DAD analysis. M. oleifera extracts were analysed by a Shimadzu HPLC (Shimadzu Corporation, Kyoto, Japan) equipped with a diode array detector (DAD) SPD-M20A (Shimadzu Corporation). Analytes were separated using a Kynetex C18 column $2.6 \mu \mathrm{m}$ x 75x2.1 mm (Phenomenex, Torrance, CA, USA). Data acquisition and peak integration were performed with a LabSolutions software (Shimadzu Corporation). The mobile phases used were $1 \%$ trifluoroacetic acid at pH 2.5 (solvent A) and acetonitrile (solvent B). The system was run with the following gradient elution program: 0 min, $85 \%$ solvent $\mathrm{A} ; 2.5 \mathrm{~min} 65 \%$ solvent $\mathrm{A} ; 7 \mathrm{~min}, 25 \%$ solvent $\mathrm{A}$; $9 \mathrm{~min}, 25 \%$ solvent $\mathrm{A} ; 13.5 \mathrm{~min}, 85 \%$ solvent $\mathrm{A}$; and $25 \mathrm{~min}, 85 \%$ solvent $\mathrm{A}$. The flow rate was kept constant throughout the analysis at $1 \mathrm{ml} / \mathrm{min}^{-1}$, and the injection volume was $20 \mu \mathrm{l}$. Chromatographic profiles were obtained at $254 \mathrm{~nm}$.

Total simple phenol and flavonoid content. The amount of total simple phenols and flavonoids in the plant samples was measured using a method that has been widely reported $(27,28)$. Briefly, for total simple phenols quantitation, the equivalent of $400 \mu \mathrm{g}$ of plant extract was mixed with $100 \mu \mathrm{l}$ of Folin-Ciocalteu reagent and $80 \mu \mathrm{l}$ of $0.7 \mathrm{M} \mathrm{Na}_{2} \mathrm{CO}_{3}$, incubated for $1 \mathrm{~h}$ in the dark and spectrophotometrically analysed at $760 \mathrm{~nm}$. For the measurement of flavonoid levels, the equivalent of $400 \mu \mathrm{g}$ of plant extract was adjusted with $\mathrm{dd}_{2} \mathrm{O}$ to reach $250 \mu \mathrm{l}$ of final volume, which was added to $30 \mu \mathrm{l}$ of pure methanol, $2 \mu \mathrm{l}$ of $10 \% \mathrm{AlCl}_{3}$ and $2 \mu \mathrm{l}$ of $1 \mathrm{M} \mathrm{CH}_{3} \mathrm{CO}_{2} \mathrm{~K}$. The sample was left in the dark for $15 \mathrm{~min}$ and absorbance was read at $415 \mathrm{~nm}$. The concentration of total phenols and flavonoids was obtained by comparing the sample absorbance values with calibration curves properly obtained using adequate amounts of pure gallic acid (GA) and quercetin (Q) as standards. Consequently, the results were reported as $\mu \mathrm{g}$ of $\mathrm{GA}$ or $\mathrm{Q}$ equivalents per $100 \mathrm{mg}$ of sample fresh weight ( $\mu \mathrm{g}$ GAE or QE/100 mg SFW).

Plant small RNA pool extraction. The total small RNA pool of $M O$ (mol-small RNA pool) was extracted from $50 \mathrm{mg}$ FW of MOE seeds using NucleoSpin miRNA in accordance with the manufacturer's instructions (NucleoSpin miRNA experiments protocols $^{\circledR}$; MACHEREY-NAGEL GmbH \& Co. KG, Düren, Germany).

Reverse transcription-quantitative polymerase chain reaction analysis (RT-qPCR) analysis. The presence of microRNA purified, as reported above, from the aqueous extract of MOE-S (mol-miR) was evaluated by RT-qPCR, as has been widely reported $(29,30)$. In brief, cDNA was synthesized using a specific reverse transcription kit for microRNA (miRCURY LNA Universal RT microRNA PCR, Synthesis kit II; EXIQON; Qiagen GmbH, Hilden, Germany), according to the
Table I. miRNA sequences primers for Moringa oleifera miR pool.

\begin{tabular}{ll} 
mol miRs & \multicolumn{1}{c}{ 5'-3' sequences } \\
\hline miR-156a & CUGACAGAAGAGAGUGAGCAC \\
miR-159a & UUUGGAUUGAAGGGAGCUCUA \\
miR-159c & UUUGGAUUGAAGGGAGCUCCU \\
miR-160h & UGCCUGGCUCCCUGUAUGCCAUU \\
miR-162a & UCGAUAAACCUCUGCAUCCA \\
miR-166i & UCGGACCAGGCUUCAUUCCCCC \\
miR-167-5p & UGAAGCUGCCAGCAUGAUCUU \\
miR-168a & UCGCUUGGUGCAGGUCGGGAA \\
miR-171d & UGAUUGAGCCGUGCCAAUAU \\
miR-393a & CAUCCAAAGGGAUCGCAUUGA \\
miR-395a & CUGAAGUGUUUGGGGGAACUC \\
miR-396a & UUCCACAGCUUUCUUGAACAG \\
miR-396c & UUCCACAGCUUUCUUGAACGU \\
miR-397-5p & UCAUUGAGUGCAGCGUUGAUG \\
miR-398b & GGGUUGAUUUGAGAACAUAUG \\
miR-482b & UCUUUCCUAUCCCUCCCAUUCC \\
miR-858a & UUCGUUGUCUGUUCGACCUUG \\
miR-858b & UUCGUUGUCUGUUCGACCUUG \\
miR-2118a & CUACCGAUGCCACUAAGUCCCA
\end{tabular}

manufacturer's guidelines. To verify the absence of nucleases in the reaction and evaluate the efficiency of retro-transcription and qPCR amplification, $10^{8}$ copies of a synthetic spike-in control miRNA (UniSp6; EXIQON; Qiagen $\mathrm{GmbH}$ ) were added to each RNA sample before conversion to cDNA. qPCR was carried out in a $10 \mu \mathrm{l}$ reaction volume that included $20 \mathrm{ng}$ cDNA, 50\% SYBR green (ExiLENT SYBR ${ }^{\circledR}$ Green master mix; EXIQON; Qiagen $\mathrm{GmbH}$ ) and $1 \mu \mathrm{l}$ of a mixture containing pre-designed PCR primers specific for microRNA amplification (microRNA LNA PCR primer sets; EXIQON; Qiagen $\mathrm{GmbH}$ ). The qPCR assay was performed using a Bio-Rad (IQ5) thermal cycler (Bio-Rad Laboratories, Inc., Hercules, CA, USA). Amplification parameters were set as recommended by the instruction manual of the EXIQON pre-designed primers (Table I).

Quantification of mol-miRs was performed using the threshold cycle $(\mathrm{Ct})$ comparative method according to the MIQE guidelines (29) comparing the mol-miRs expression respect to the lower expressed miR (mol-miR858b). 5S rRNA was used as a housekeeping gene.

Statistical analysis. All data were presented as the mean \pm SD of at least three independent experiments performed on THP1 and Jurkat cells and PMBCs from 10 healthy donors. Data analyses were performed using the SPSS statistical software system (v.17.0; SPSS, Inc., Chicago, IL, USA).

Comparison between treated vs. untreated cells for trypan blue assay, apoptosis assay, BCL2 and SIRT1 intracellular protein expression were all conducted using t-test. A comparison of trypan blue apoptosis and BrdU assays results, in response to the different concentration of extracts, was carried out using an ANOVA and a Bonferroni significant difference test as a multiple comparison test. ${ }^{*} \mathrm{P}<0.05,{ }^{* *} \mathrm{P}<0.01$ 


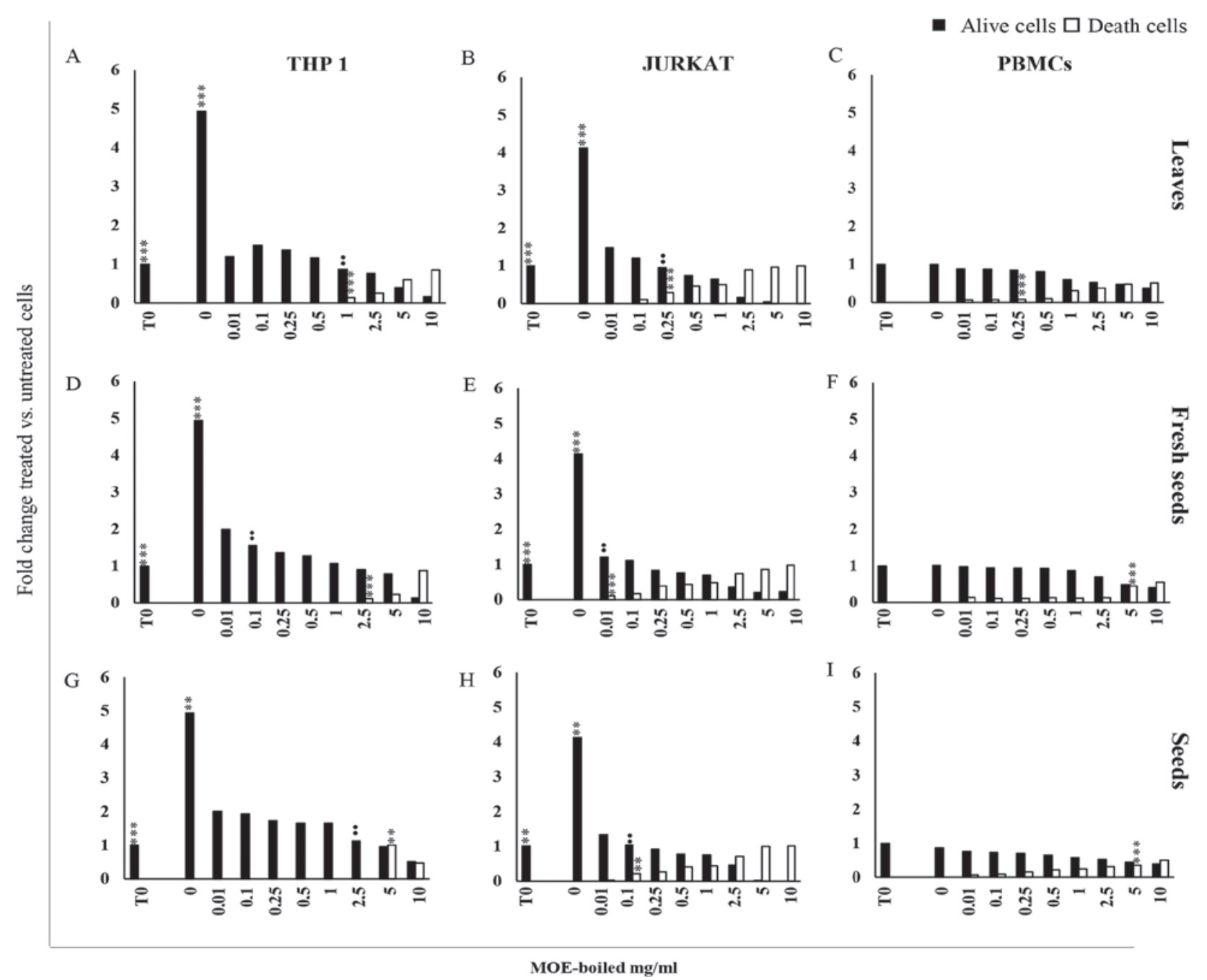

Figure 1. (A-H) Anti-proliferative effect of MO boiled extracts. Cell viability analysed by trypan blue exclusion assay in cells. (A, D, G) THP1, (B, E, H) Jurkat cells and (C, F, I) PBMCs from healthy donors treated with MOE boiled leaves, fresh seeds and seeds with a concentration ranging from 0 to $10 \mathrm{mg} / \mathrm{ml}$ for $72 \mathrm{~h}$. Control cells $(0 \mathrm{mg} / \mathrm{ml})$ were incubated for the same amount of time with an equivalent volume of water. The results are expressed as fold change histograms of trypan blue positive (white square) or negative cells (black square) with respect to cells at time 0 . Data are reported as the mean of three different experiments and of 17 healthy donors' PBMCs \pm SD. Symbols indicate significant differences: ${ }^{* *} \mathrm{P}<0.01,{ }^{* * * *} \mathrm{P}<0.001$ all treatment vs. untreated cells. ${ }^{*} \mathrm{P}<0.01$ represent the lowest concentration able to significantly reduce or increase cell viability or death, respectively.

and ${ }^{* * *} \mathrm{P}<0.001$ were considered to indicate a statistically significant difference. For non-parametric correlations, a Pearson correlation coefficient was calculated.

\section{Results}

Effects of different preparations of $M$. oleifera leaves and seeds on THP1 cells, Jurkat cells and PBMCs from healthy donors. To obtain information about MO's effect on cell viability, Jurkat cells, THP1 cells and PBMCs were treated with extracts obtained from the leaves (L), seeds (S) and fresh seeds (FS) of $M O$, after being frozen (MOE-f) or boiled in water (MOE-b).

THP1 and Jurkat cells and PBMCs from healthy donors were treated with frozen or boiled MOE in a concentration ranging from 0 to $10 \mathrm{mg} / \mathrm{ml}$.

Seventy-two hours after treatment, cell viability was analysed using a trypan blue assay.

For each type of preparation, the MOE concentration that was able to reduce cell proliferation by $50 \%$ (EC50) or induce death in $50 \%$ of cells (LD50), with respect to the number of cells at time 0 , was estimated.

Effects of $M$. oleifera extracts obtained by boiling on cell viability. After $72 \mathrm{~h}$, the treatment of THP1 (Fig. 1A, D and G) and Jurkat (Fig. 1B, E and H) cells with boiled extracts of the three different parts of the MO plant induced a significant reduction of proliferation, with respect to untreated cells, in a dose dependent manner, starting from $0.01 \mathrm{mg} / \mathrm{ml}(\mathrm{P}<0001$ for each concentration vs. untreated cells; Fig. 1).

Jurkat and THP1 cells showed a different susceptibility to MOE treatments: Although MOE-b reduced cell growth in both tumour cells at a low concentration, it showed a lower toxicity in THP1 cells with respect to Jurkat cells. Indeed, THP1 cells demonstrated a significant increase in trypan blue positive cells at a concentration of $1 \mathrm{mg} / \mathrm{ml}$ for leaves (Fig. 1A), $2.5 \mathrm{mg} / \mathrm{ml}$ for fresh seeds (Fig. 1D) and $5 \mathrm{mg} / \mathrm{ml}$ for seeds (Fig. 1G), whereas a cytotoxic effect was evident in Jurkat cells starting from $0.25 \mathrm{mg} / \mathrm{ml}$ of leaves (Fig. 1B), $0.01 \mathrm{mg} / \mathrm{ml}$ of fresh seeds (Fig. 1E), and $0.1 \mathrm{mg} / \mathrm{ml}$ of seeds (Fig. 1H). 
Table II. EC50 of boiled extracts of Moringa oleifera $(\mathrm{mg} / \mathrm{ml})$.

\begin{tabular}{lccc}
\hline & THP1 & JURKAT & PBMC \\
\hline Leaves & $0.015 \pm 0.001$ & $0.129 \pm 0.050$ & $1.94 \pm 0.50$ \\
Fresh seeds & $0.014 \pm 0.010$ & $0.035 \pm 0.050$ & $>10$ \\
Seeds & $0.020 \pm 0.001$ & $0.121 \pm 0.020$ & $>10$ \\
\hline
\end{tabular}

Table III. LD50 of boiled extracts of Moringa oleifera $(\mathrm{mg} / \mathrm{ml})$.

\begin{tabular}{lccc}
\hline & THP1 & JURKAT & PBMC \\
\hline Leaves & $>10$ & $2.790 \pm 1.550$ & $>10$ \\
Fresh seeds & $>10$ & $2.010 \pm 1.180$ & $>10$ \\
Seeds & $>10$ & $3.860 \pm 2.680$ & $>10$ \\
\hline
\end{tabular}

MOE treatments at a low concentration preserved viability in PBMCs from healthy donors; a decrease of cell proliferation associated with a significant increase of trypan blue positive cells was detectable at the concentration of $0.25 \mathrm{mg} / \mathrm{ml}$ for leaves (Fig. 1C) and $5 \mathrm{mg} / \mathrm{ml}$ for all seed preparations (Fig. 1F-I).

Based on these results, EC50 at $72 \mathrm{~h}$ of MOE treatment was calculated compared to control cells.

As shown in Table II, THP1 cells were the most sensitive to treatments with the different boiled parts of M. oleifera. In fact, for all boiled preparations, a concentration between 0.014 and $0.020 \mathrm{mg} / \mathrm{ml}$ was enough to reduce proliferation of THP1 cells by $50 \%$, whereas for Jurkat cells, concentrations of $0.129,0.121$ and $0.035 \mathrm{mg} / \mathrm{ml}$ for leaves, seeds and fresh seeds, respectively, were necessary to reduce proliferation by $50 \%$. PBMCs appeared to be less sensitive to the treatments: Concentrations of $1.94 \mathrm{mg} / \mathrm{ml}$ of leaves and of more than $10 \mathrm{mg} / \mathrm{ml}$ of all seed extracts were required to reach the EC50 value.

The different MO tissue boiled extracts induced the death of 50\% of cells (LD50) more effectively in Jurkat cells with respect to THP1 cells and PBMCs. In detail, LD50 in THP1 cells and PBMCs was obtained for an MOE concentration of higher than $10 \mathrm{mg} / \mathrm{ml}$, while a concentration between 2-4 $\mathrm{mg} / \mathrm{ml}$ was sufficient in Jurkat cells (Table III).

Effects of M. oleifera extracts obtained by freezing on cell proliferation. The treatment of THP1 and Jurkat cells with frozen extracts of the three different parts of the MO plant induced a significant reduction of proliferation, in a dose dependent manner, starting from $0.01 \mathrm{mg} / \mathrm{ml}(\mathrm{P}<0001$ for each concentration vs. untreated cells; Fig. 2). The treatment became cytotoxic with a different intensity in THP1 cells with respect to Jurkat cells: For THP1 cells starting from $5 \mathrm{mg} / \mathrm{ml}$ for leaves, $2.5 \mathrm{mg} / \mathrm{ml}$ for seed samples (Fig. $2 \mathrm{~A}$ and $\mathrm{G}$ ), and from $1 \mathrm{mg} / \mathrm{ml}$ for fresh seed preparations (Fig. 2D) and in Jurkat cells starting at $0.1 \mathrm{mg} / \mathrm{ml}$ for all preparations (Fig. 2B, E, H).

A reduction of viable PBMCs was observed when they were exposed to $2.5-10 \mathrm{mg} / \mathrm{ml}$ of leaves and fresh seeds (Fig. $2 \mathrm{C}$ and F) and $0.25-10 \mathrm{mg} / \mathrm{ml}$ of the seed preparation
(Fig. 2I). In PBMCs, the cytotoxic effect of frozen MOE appeared at high concentration $(5-10 \mathrm{mg} / \mathrm{ml})$ for the treatment with L and FS (Fig. 2C and F), while S extract promoted the development of trypan blue positive cells starting from $0.1 \mathrm{mg} / \mathrm{ml}$ (Fig. 2I).

EC50 values were also measured for the treatments using frozen preparations of leaves, fresh seeds and seeds of MOE (Table IV).

EC50 of frozen MOE in THP1 and Jurkat cells is within a concentration range of $0.001-0.019 \mathrm{mg} / \mathrm{ml}$. As well as for boiled extracts, PBMCs were less sensitive to the treatments. Indeed, for these cells, higher concentrations of extracts, with respect to tumour cell lines, were necessary to reduce cell proliferation by $50 \%$ (in detail, $5.195 \mathrm{mg} / \mathrm{ml}$ for L, $2.895 \mathrm{mg} / \mathrm{ml}$ for FS and $1.065 \mathrm{mg} / \mathrm{ml}$ for $\mathrm{S}$ ).

Frozen MOE also showed a higher LD50 value in Jurkat cells than in THP1 cells and PBMCs (Table V).

In THP1 cells and PBMCs, a concentration higher than $10 \mathrm{mg} / \mathrm{ml}$ was necessary to reach LD50, while in Jurkat cells, a dose between $0.1-0.8 \mathrm{mg} / \mathrm{ml}$ was sufficient to induce death in $50 \%$ of cells.

Taken together, these data suggest that Jurkat and THP1 cells are more sensitive than PBMCs to treatment with MO aqueous extracts obtained by boiling, as well as freezing, in terms of cell proliferation.

Moreover, Jurkat cells were the most sensitive in terms of cytotoxic effect, compared to THP1 cells and PBMCs. In particular, in Jurkat cells, MOE-f was more toxic than MOE-b; indeed, a 10-fold lower concentration of all types of plant parts, in MOE-f with respect to MOE-b, was sufficient to reach the LD50 value.

Effects of different preparations of M. oleifera leaves and seeds on the apoptosis of THPI cells, Jurkat cells and PBMCs from healthy donors. To evaluate the effects of $M$. oleifera aqueous extracts on apoptosis, PBMCs from healthy donors and THP1 and Jurkat cells were treated with boiled and frozen aqueous preparations of different plant parts in a concentration ranging from 0 to $10 \mathrm{mg} / \mathrm{ml}$. After $72 \mathrm{~h}$, the apoptotic level was measured by assessing the percentage of hypodiploid nuclei, through propidium iodide (PI) staining and flow cytometry analysis.

Effects of M. oleifera boiled extracts on apoptosis. The results obtained after cells were treated with MO boiled extracts are shown in Fig. 3. Among MOE-b, treatment with the L preparation induced a high level of apoptosis in both cell lines and PBMCs. The treatment increased the hypodiploid nuclei in THP1 cells by approximately $20 \%$ starting at a concentration of $0.5 \mathrm{mg} / \mathrm{ml}$, while in Jurkat cells, a concentration twice as high $(1 \mathrm{mg} / \mathrm{ml})$ was necessary to have the same apoptotic level.

The PBMCs were less sensitive to MOE-b; $2.5 \mathrm{mg} / \mathrm{ml}$ of extracts were required to induce apoptosis of approximately $25 \%$ in treated cells (Fig. 3A).

The fresh seed preparation induced significant apoptotic levels only in THP1 cells, while it did not affect Jurkat cells or PBMCs, in which only higher concentrations induced a significant effect (Fig. 3B).

The effects of treatment with $\mathrm{S}$ boiled extracts were highly variable, depending on cell type. In THP1 cells, a significant increase in apoptotic level (20\% of hypodiploid nuclei) from a 


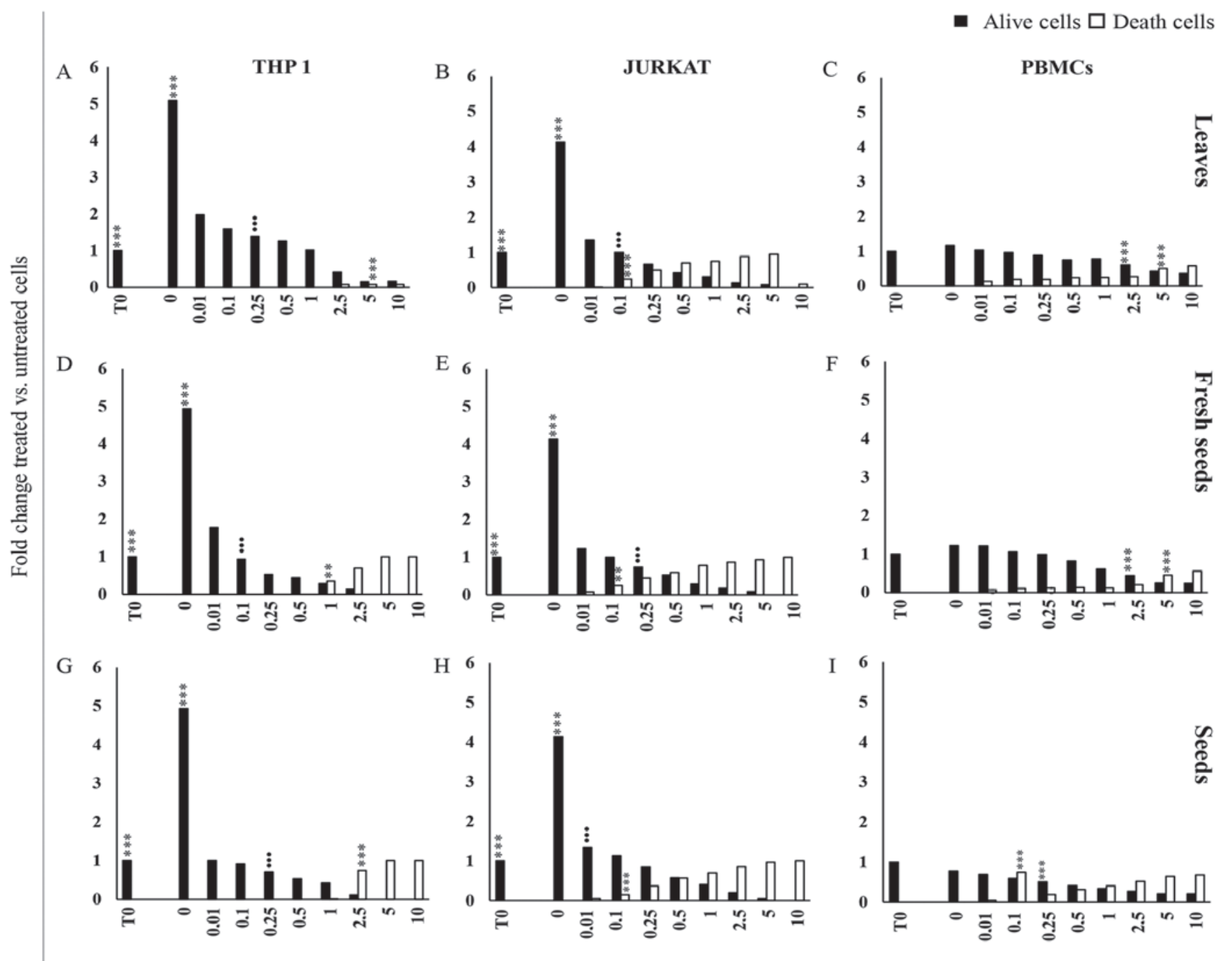

MOE-frozen $\mathrm{mg} / \mathrm{ml}$

Figure 2. Anti-proliferative effect of MO frozen extracts. Cell viability. (A, D, G) THP1, (B, E, H) Jurkat cells and (C, F, I) PBMCs from healthy donors after treatment with MOE frozen leaves, fresh seeds and seeds, at a concentration of 0 to $10 \mathrm{mg} / \mathrm{ml}$ for $72 \mathrm{~h}$ and analysed by trypan blue exclusion test. Control cells $(0 \mathrm{mg} / \mathrm{ml})$ were incubated for the same time with an equivalent volume of water. The results are expressed as a fold change of trypan blue positive (black square) or negative cells (white square) with respect to cells at time 0 . Data are reported as the mean of three different experiments and of 17 healthy donors PBMCs \pm SD. Symbols indicate significant differences: ${ }^{* *} \mathrm{P}<0.01,{ }^{* * *} \mathrm{P}<0.001$ all treatment vs. untreated cells. ${ }^{\cdots} \mathrm{P}<0.001$ represent the lowest concentration able to significantly reduce or increase cell viability or death, respectively.

concentration of $0.01 \mathrm{mg} / \mathrm{ml}$ was observed, while Jurkat cells needed $1 \mathrm{mg} / \mathrm{ml}$ of Fresh Weight $(\mathrm{FW})$ to be affected by this treatment.

Interestingly, the boiled $\mathrm{S}$ preparation showed a specific pro-apoptotic effect on tumour cells, compared to the PBMCs of healthy donors, which were particularly resistant to the treatment. In fact, in PBMCs, the apoptotic level never exceeded $10 \%$, even at the highest concentration used (10 mg/ml) (Fig. 3C).

Taken together, these results emphasized the non-significant $(\mathrm{P}>0,05)$ pro-apoptotic effect of the boiled mature seed preparation on lymphocytes from healthy donors, in contrast to the significant effect observed in the two tumour cell lines analysed.

In particular, we have also demonstrated that THP1 cells were more sensitive to the treatments in a dose dependent manner, while Jurkat cells appeared to be more resistant.

Effects of M. oleifera frozen extracts on apoptosis. The evaluation of apoptosis after $72 \mathrm{~h}$ of treatment with MOE-f preparations underlined the high toxic effect of all these extracts on both cell lines and lymphocytes from healthy donors (Fig. 4).

Treatment with the frozen preparation of leaves induced a high level of apoptosis in all analysed cells. In particular, it increased the hypodiploid nuclei by approximately $25 \%$ with respect to the untreated cells; in THP1 cells, this increase occurred starting at a concentration of $2.5 \mathrm{mg} / \mathrm{ml}$ and in Jurkat cells, $5 \mathrm{mg} / \mathrm{ml}$ of FW induced approximately $50 \%$ of apoptosis.

The PBMCs were less sensitive; $5 \mathrm{mg} / \mathrm{ml}$ of $M O$ was required to reach a $20 \%$ level of apoptosis (Fig. 4A).

The fresh seed preparation demonstrated a significant increase in apoptosis in THP1 and Jurkat cells at a low concentration. In detail, in THP1 cells, a significant increase of $30 \%$ in the apoptosis level, starting at a concentration of $0.25 \mathrm{mg} / \mathrm{ml}$, was observed, while in Jurkat cells, we observed an $80 \%$ increase in apoptosis at a concentration of $0.5 \mathrm{mg} / \mathrm{ml}$.

Interestingly, PBMCs from healthy donors were particularly resistant to the treatment. 
Table IV. EC50 of frozen extracts Moringa oleifera $(\mathrm{mg} / \mathrm{ml})$.

\begin{tabular}{llcc}
\hline & \multicolumn{1}{c}{ THP1 } & JURKAT & PBMCs \\
\hline Leaves & $0.019 \pm 0.001$ & $0001 \pm 0.003$ & $5.195 \pm 0.890$ \\
Fresh seeds & $0.010 \pm 0.01$ & $0.010 \pm 0.001$ & $2.895 \pm 1.300$ \\
Seeds & $0.010 \pm 0.003$ & $0.011 \pm 0.010$ & $1.065 \pm 1.840$ \\
\hline
\end{tabular}

Table V. LD50 Moringa oleifera Frozen extract (mg/ml).

\begin{tabular}{lccc}
\hline & THP1 & JURKAT & PBMC \\
\hline Leaves & $>10$ & $0.145 \pm 0.230$ & $>10$ \\
Fresh seeds & $>10$ & $0.275 \pm 0.140$ & $>10$ \\
Seeds & $>10$ & $0.785 \pm 0.500$ & $>10$ \\
\hline
\end{tabular}

In fact, the apoptosis level in these cells never exceeded $10 \%$, even at the highest concentration (5-10 mg/ml; Fig. 4B).

In THP1 cells, treatment with seed preparation induced a significant increase in apoptosis (25\% of hypodiploid nuclei) starting at a concentration of $0.01 \mathrm{mg} / \mathrm{ml}$; in Jurkat cells and PBMCs, $1 \mathrm{mg} / \mathrm{ml}$ of FW was necessary to reach this level of apoptosis (Fig. 4C).

These results confirm the results obtained on cell proliferation and cytotoxicity: MOE-f preparations were more toxic than MOE-b preparations in all cells analysed.

Characterization of the anti-proliferative and pro-apoptotic effects of MOE-S- $b$. Considering the inclusion of MO seeds in the List of Plant and Vegetable Integrators, in respect to the European Pharmaceutical Plant Legislation, and their low cytotoxic effects (Tables II-III), the anti-proliferative and pro-apoptotic activities of $M O$ seeds on Jurkat cells were characterized in detail.

After $72 \mathrm{~h}$ of treatment, a significant reduction in viability and an increase in apoptosis level were observed in Jurkat cells (Fig. 5A). Moreover, MOE-S-b induces a significant reduction in DNA synthesis compared to untreated cells, as demonstrated by the BrdU assay (Fig. 5B).

Pearson's correlation analysis of all these data show that the reduction of DNA synthesis correlated with the decreased number of viable cells (Fig. 5C) and the increase of apoptotic cells (Fig. 5D) treated with MOE-S.

The pro-apoptotic effect, induced by $1 \mathrm{mg} / \mathrm{ml} \mathrm{FW}$ of MOE-S in Jurkat cell lines, was further investigated, evaluating the expression of SIRT1 and BCL2 proteins through flow cytometry analysis. The treatment of Jurkat cells with MOE-S-b induced a significant decrease of alive cells that express BCL2 and SIRT1 anti apoptotic proteins. This significant reduction was observed analysing the median intensity fluorescence (MIF) and the percentage of BCL2 (Fig. 5E-G) and SIRT1 protein expression (Fig. 5H-J).

HPLC analysis: Total simple phenols and flavonoid content. To better understand and explain the previously observed biological activity of MOE-S on human cells, we analysed the HPLC-DAD chemical profiles of MOE-S and measured their total concentrations of simple phenols and flavonoids by spectrophotometric assays.

HPLC-DAD analysis demonstrated that L (green line), FS (pink line) and $\mathrm{S}$ (black line) samples presented very different chemical profiles (Fig. 6). In particular, L extracts appeared richer in secondary metabolites than FS and S preparations, which only showed little chromatographic peaks. In detail, all L extracts showed several secondary metabolites with retention times of between 9 and $12.5 \mathrm{~min}$, which were not present in $\mathrm{MO}$ seed extracts. Likely, these peaks could be flavonoids, due to their higher affinity with the apolar B solvent used during the analysis. Generally, all profiles were richer in the initial part of the chromatogram with respect to the second part, indicating that polar compounds, including sugars, were abundant in all extracts. Surprisingly, we also observed that the metabolic profiles of each sample (L, FS and S) varied greatly according to the extraction method (boiled or frozen; Fig. 6A and B, respectively), in qualitative and quantitative terms. The boiling method appeared, on average, to better preserve the MO secondary metabolites in the extracts than the freezing procedure.

Spectrophotometric analysis measured the total amount of phenols and flavonoids in MOE (Fig. 6C). L preparations had more phenols and flavonoids than FS and S ones, both in boiled and in frozen extracts, confirming the previous HPLC-DAD observation. In particular, the amount of flavonoids was higher than simple phenols in L samples, supporting the existence of peaks at a high retention time in the chromatographic analysis of these extracts. In S and FS samples, simple phenols were more concentrated than flavonoids. However, S samples were generally richer in both of these two classes of plant compounds than the FS extract.

Results also demonstrated that the frozen preparation protocol degraded flavonoids but not simple phenols in $\mathrm{L}$ extracts, with respect to the boiling procedure, while it did not influence the concentration of secondary metabolites in FS and $\mathrm{S}$.

microRNA expression profile of $M$. oleifera seed aqueous extract. A recent publication characterised the natural Olea europea small RNAs profile in olive drupes highlighting the presence of the most conserved plant miRNAs. The study demonstrated the effects of this small RNAs pool on apoptosis and proliferation in tumors cells (12).

Based on this result and on our recent paper reporting the miRNome of MO seeds $(31,32)$, the mol-small RNA pool was extracted from MOE-b seeds and the presence of plant mol-miR was evaluated.

In this extract the qRT-PCR analysis revealed the presence of plant miRNAs (Fig. 7) belonging to 40 conserved families of plant microRNAs (32) involved in different important plant cellular pathways such as the response to abiotic stress, growth, differentiation and cell proliferation (32-34) (http://www.mirbase.org/search). This result suggests their possible involvement in apoptosis and proliferation, previously observed with Olea europea small RNAs.

\section{Discussion}

In the last years, different studies have been performed to confirm the beneficial effects of MO on humans $(6,35,36)$. 


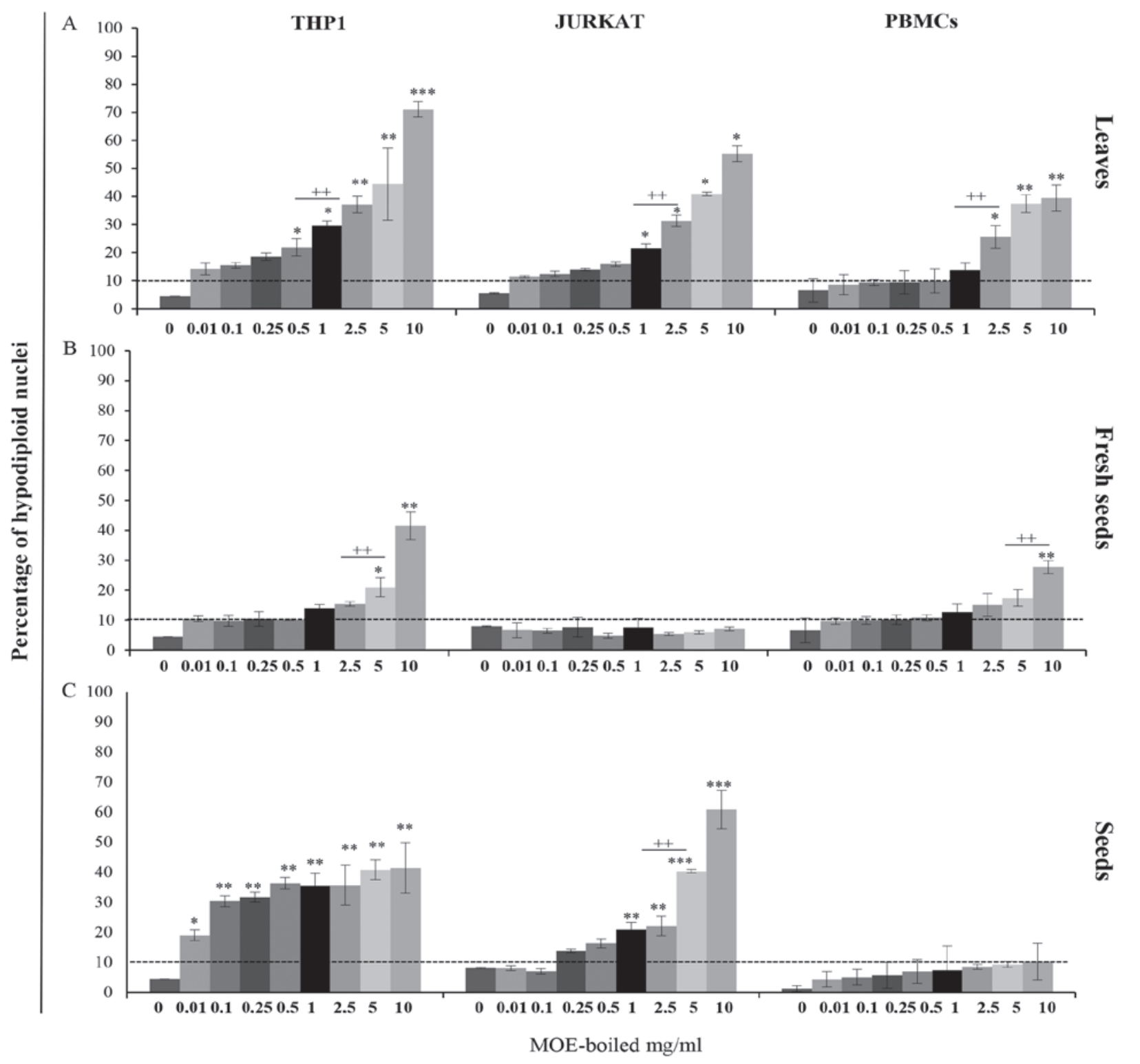

Figure 3. Effect of boiled extract on apoptosis in THP1 cells, Jurkat cells and PBMCs. All cells were treated with boiled preparations of MOE (A) leaves, (B) fresh seeds or (C) seeds at a concentration ranging from 0 to $10 \mathrm{mg} / \mathrm{ml}$ for $72 \mathrm{~h}$. The data on the Y-axis are expressed as percentage of hypodiploid nuclei detected by propidium iodide staining through flow-cytometry analysis. Data are reported as the mean of three independent experiments and of 17 healthy donors' PBMCs \pm SD. Symbols indicate significant differences: ${ }^{*} \mathrm{P}<0.05,{ }^{* *} \mathrm{P}<0.01,{ }^{* * * *} \mathrm{P}<0.001$ all treatment vs. untreated cells. ${ }^{+} \mathrm{P}<0.01$ represents the lowest concentration able to induce a significant increase in apoptosis in treated cells.

MO is used for medicinal purposes, as well as for human nutrition, since this plant is rich in antioxidants and other nutrients, which are commonly deficient in people living in undeveloped countries $(22,23,37)$. Moreover, MO showed chemo-preventive properties, being able to inhibit the growth of several human cancer cells (38). Indeed, different studies have recognized the anti-proliferative and pro-apoptotic effects of $M$. oleifera extracts $(17,38,39)$, but they have not explained the mechanisms underlying the phenomena.

According to this evidence, the aim of the present study was the evaluation of the biological effects of $\mathrm{MO}$ on human tumour cell lines and PBMCs from healthy donors.

Several studies have shown that the use of various organic and inorganic solvents allow for the isolation of several active components from plant tissues $(7,40)$. For this reason, we investigated the bioactivity of different types of MO extracts on proliferation and apoptosis mechanisms. Plant extracts were produced from MO leaves, seeds and fresh seeds, by both simulating the traditional method used in African traditional medicine (hot water maceration) and frozen extraction (obtained by freezing the plant material in water).

MO extracts obtained by boiling the plant material demonstrated a significant decrease of cell proliferation of Jurkat and THP1 cell lines, in a dose dependent manner, while MO preparations produced by freezing plant material, demonstrated a significant decrease in cell proliferation in both tumour cell lines at a low concentration.

The cytotoxic effect of the MO extracts was dependent on the cell type. Jurkat cells were more susceptible than THP1 cells to all MOE-b preparations; indeed, $2-4 \mathrm{mg} / \mathrm{ml}$ of these extracts were necessary to induce $50 \%$ cell death, while for 


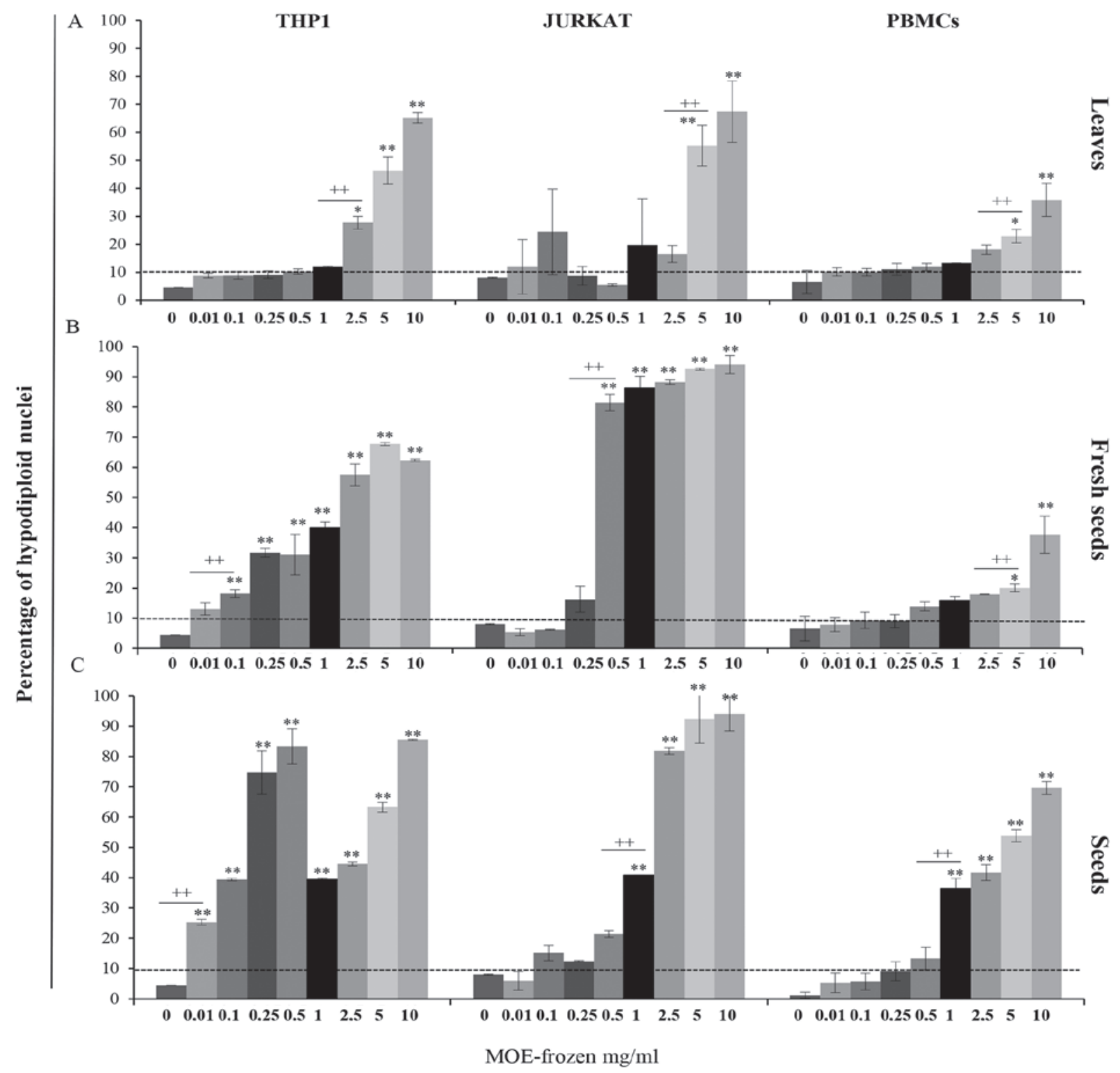

Figure 4. Effect of frozen extract on apoptosis in THP1 cells, Jurkat cells and PBMCs. All cells were treated with frozen preparations of MO (A) leaves, (B) fresh seeds or (C) seeds at a concentration ranging from 0 to $10 \mathrm{mg} / \mathrm{ml}$ for $72 \mathrm{~h}$. The data on the Y-axis are expressed as percentage of hypodiploid nuclei detected by propidium iodide staining through flow-cytometry analysis. Data are reported as the mean of three independent experiments and of 17 healthy donors' PBMCs \pm SD. Symbols indicate significant differences: ${ }^{*} \mathrm{P}<0.05,{ }^{* *} \mathrm{P}<0.01,{ }^{* * * *} \mathrm{P}<0.001$ all treatment vs. untreated cells. ${ }^{+} \mathrm{P}<0.01$ represents the lowest concentration able to induce a significant increase in apoptosis in treated cells.

THP1 cells and PBMCs, $10 \mathrm{mg} / \mathrm{ml}$ was necessary to reach the same effect.

Similarly, all MOE-f preparations were more toxic in the Jurkat cell line than in THP1 cells and PBMCs from healthy donors.

In particular, MOE-b revealed a specific anti-proliferative activity on tumour cells but not on PBMCs, which were not affected by this treatment.

The information obtained on cell viability prompted us to analyse the main cause of the proliferation decrease induced by MO extracts. Therefore, we evaluated the apoptosis in cell lines treated with MOE-b and MOE-f, analysing the percentage of hypodiploid nuclei.

Our studies showed that, generally, MOE-b preparations were less toxic than MOE-f preparations. Jurkat and THP1 cell lines and PBMCs treated with boiled extracts showed a significant dose-dependent increase of apoptosis in all analysed cells.

As boiled extracts were the least toxic, we decided to select them for further investigation. Interestingly, MOE-b seeds showed, with respect to the other parts of plant (leaves and fresh seeds), a more specific pro-apoptotic effect on tumour cell lines compared to PBMCs from healthy donors, which were particularly resistant to this treatment.

Considering the inclusion of MO seeds in the List of Plant and Vegetable Integrators, in respect to the European Pharmaceutical Plant Legislation, and their low cytotoxic effects previously described, our studies were focused on the characterization of the boiled aqueous extract of Moringa oleifera seeds. The experiments conducted with MOE-S showed that $1 \mathrm{mg} / \mathrm{ml} \mathrm{FW}$ of MOE-S induces a decrease of BCL2 and SIRT1 protein expression associated 
A

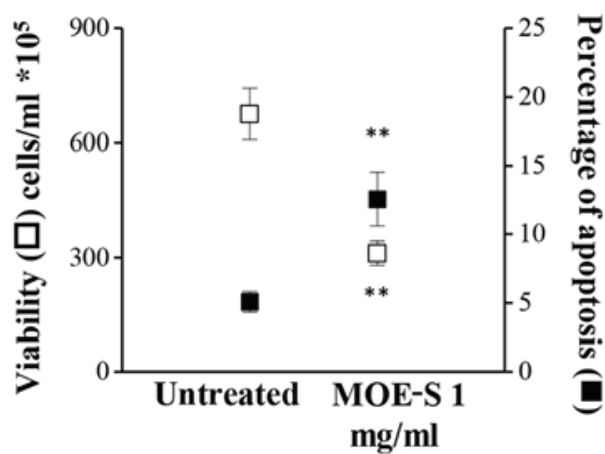

C

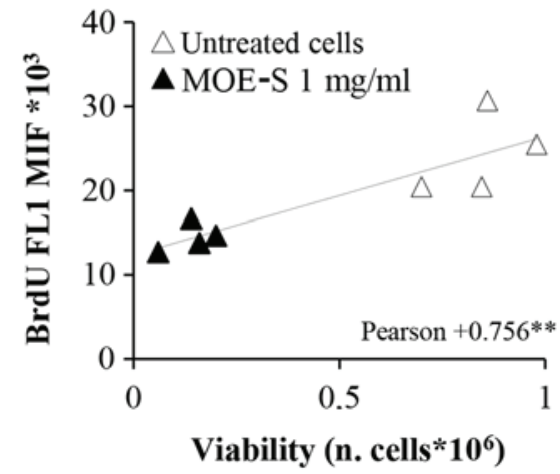

B

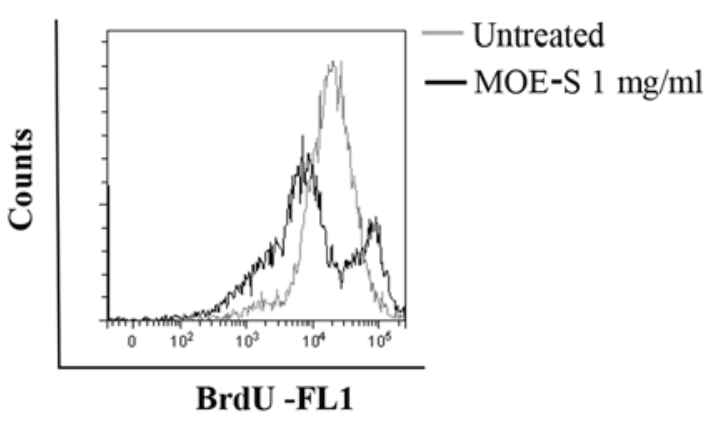

D

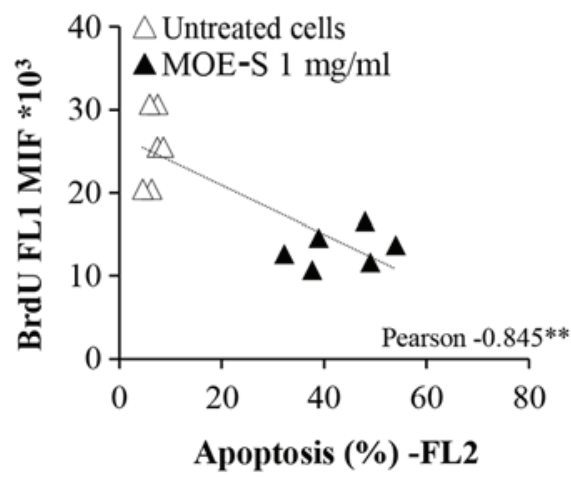

$\mathbf{E}$ Untreated MOE-S $1 \mathrm{mg} / \mathrm{ml}$

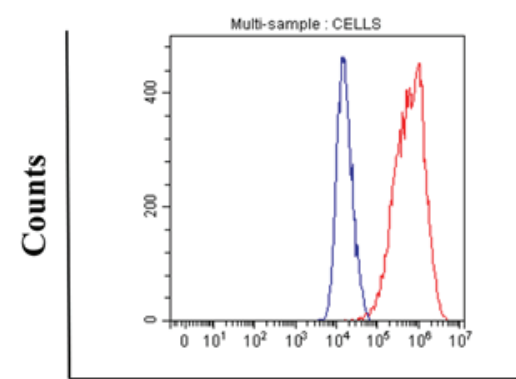

BCL2- FL1
$\mathbf{F}$

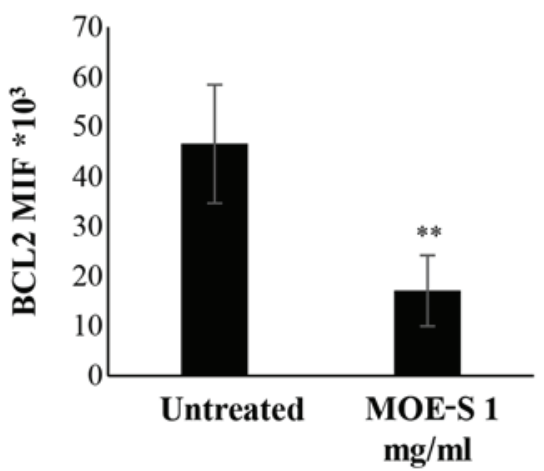

I

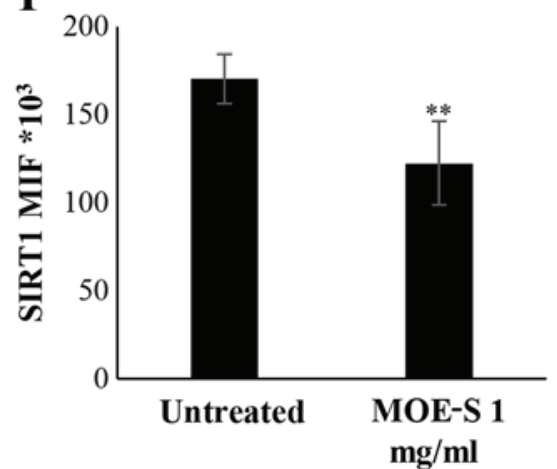

G
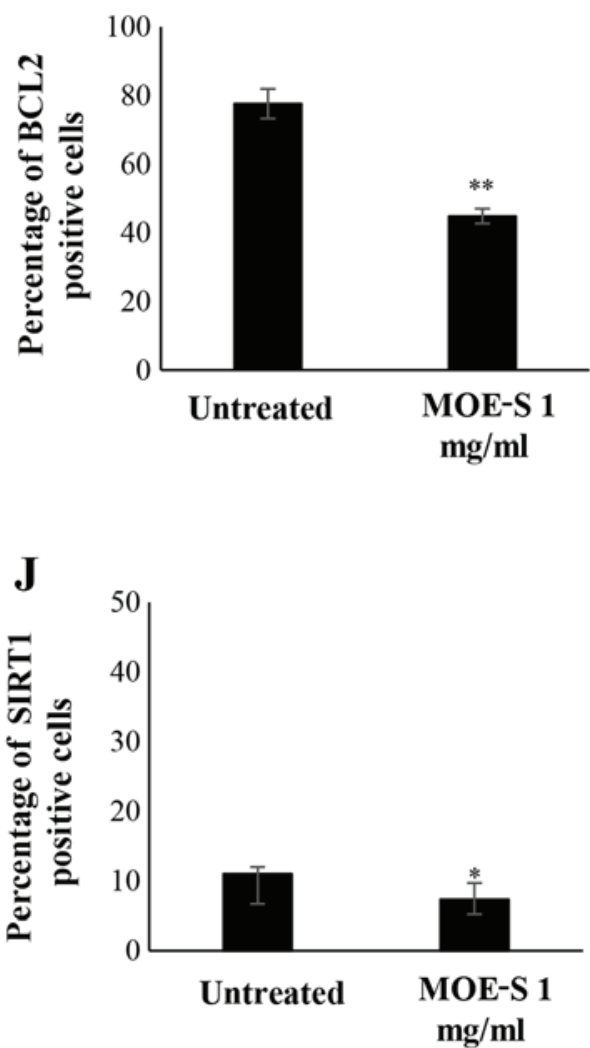

Figure 5. Characterization of the pro-apoptotic and anti-proliferative effects of MOE-S. (A) Jurkat cells were treated with $1 \mathrm{mg} / \mathrm{ml}$ FW of MOE boiled seeds for $72 \mathrm{~h}$. Viability and apoptosis were analysed and reported as number of alive cells $\mathrm{x} 10^{5} / \mathrm{ml}$ (white square) and percentage of apoptosis (black square) respectively. The reduction of DNA synthesis was characterized by bromodeoxyuridine assay: One representative overlay histogram (B) of BrdU-positive cells in untreated cells (grey line) and MOE-S (black line), analysed by Flow cytometry. Correlation analysis of DNA synthesis with respect to (C) cell viability and (D) apoptosis. (E) Representative overlay histogram of BCL2 protein expression. (F) Median intensity fluorescence (MIF) of BCL2 positive cells from three independent biological experiments. (G) The percentage of BCL2 positive cells was represented by a histogram of three independent biological experiments. (H) BCL2 overlay histogram of SIRT1 protein expression, (I) MIF of SIRT1 positive cells and (J) percentage of SIRT1 positive cells. Data are reported as the mean $\pm \mathrm{SD}$ of three independent experiments performed. ${ }^{*} \mathrm{P}<0.05,{ }^{* *} \mathrm{P}<0.01$, treated vs. untreated cells. 
A

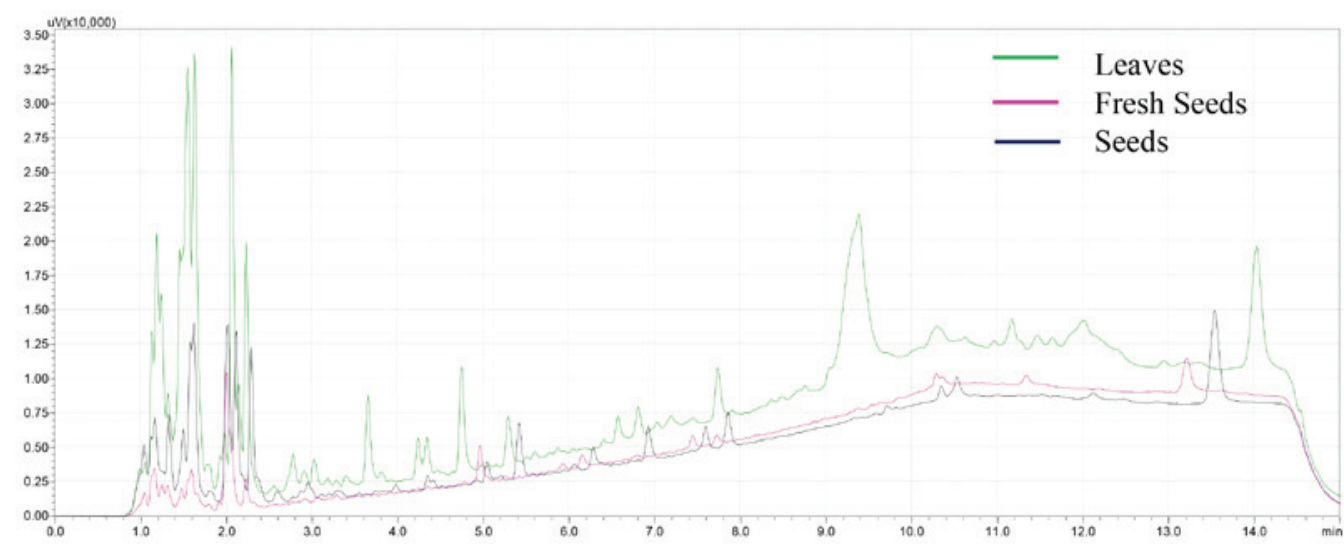

B

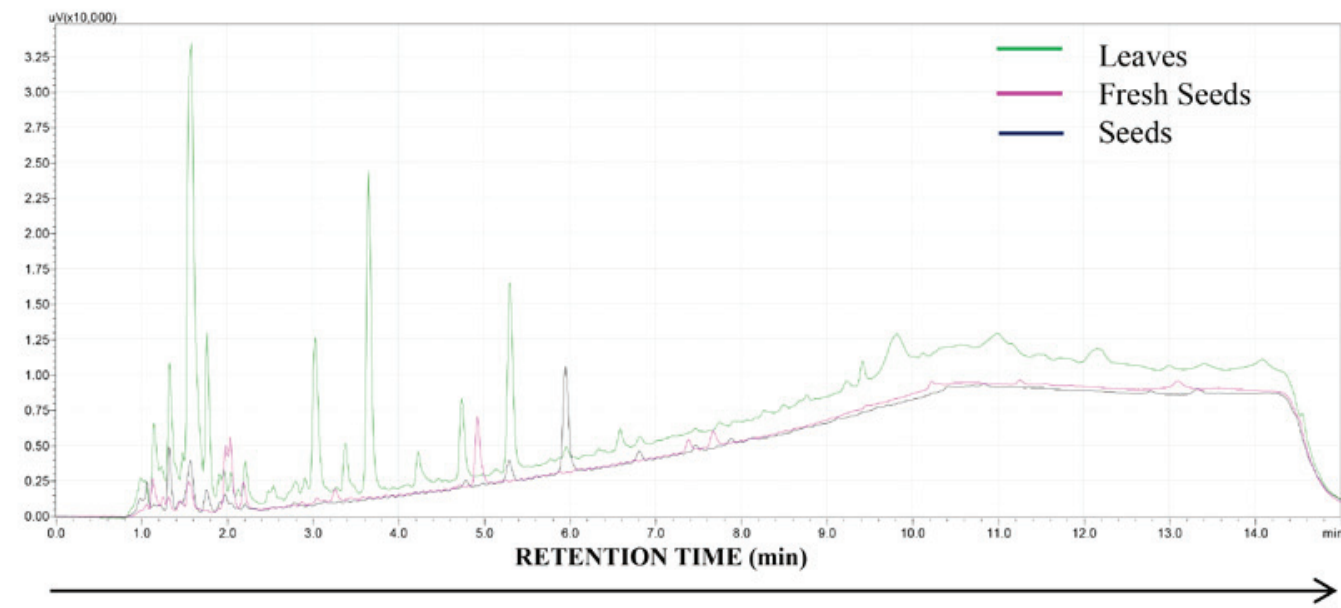

C

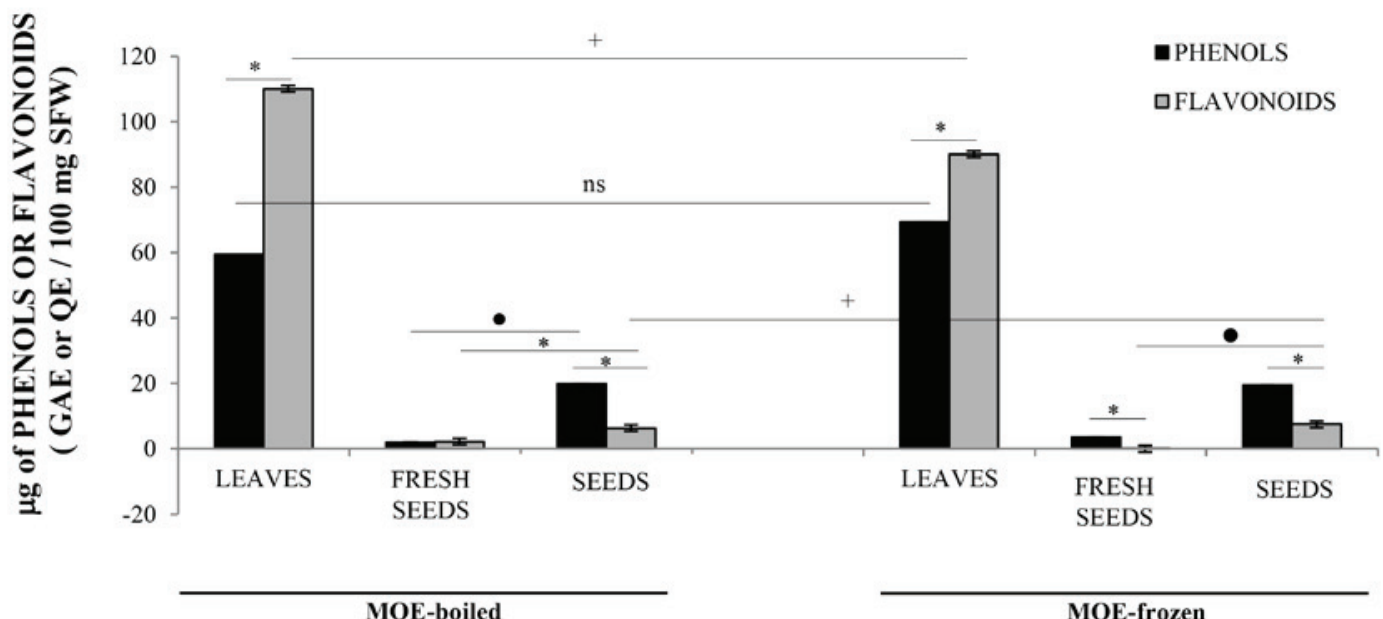

Figure 6. Analysis of the HPLC profile of leaves and seeds. HPLC-DAD chromatograms, observed at $254 \mathrm{~nm}$, of (A) boiled MOE of seeds (black line), fresh seeds (pink line) and leaves (green line). HPLC chromatograms, observed at $254 \mathrm{~nm}$, of (B) frozen MOE of seeds (black line), fresh seeds (pink line) and leaves (green line). The results obtained by spectrophotometric analyses were reported; in particular, (C) the total simple phenol and flavonoid concentrations measured in leaves, seeds and fresh seeds of MOE-b and MOE-f were shown. These results were expressed as $\mu \mathrm{g}$ of gallic acid (GA) and quercetin equivalents (Q) for total phenol and flavonoid quantitation, respectively, per $100 \mathrm{mg}$ of sample fresh weight ( $\mu \mathrm{g} \mathrm{GAE}$ or QE/100 $\mathrm{mg} \mathrm{SFW}$ ). Each value represents the mean of three independent determinations $\pm \mathrm{SD}$. ${ }^{*} \mathrm{P}<0.05$, represent the differences between phenol and flavonoid amount in the different parts of plant. ${ }^{+} \mathrm{P}<0.05$ represent the differences of phenol and flavonoid amount in leaves, fresh seeds and seeds. ${ }^{\circ} \mathrm{P}<0.05$ represent the differences of phenol or flavonoid amount between fresh seeds and seeds in MOE-boiled as well as in MOE frozen.

with the enhancement of apoptosis and the anti-proliferative effect mediated by the downregulation of DNA synthesis.

To obtain qualitative and quantitative data about MOE biochemical compounds, we conducted HPLC-DAD analyses on MO preparations. These investigations allowed us to reveal the chemical profiles of boiled and frozen extracts, demonstrating that, in both cases, seeds and fresh seed samples had a different biochemical profile compared to the leaves, although 


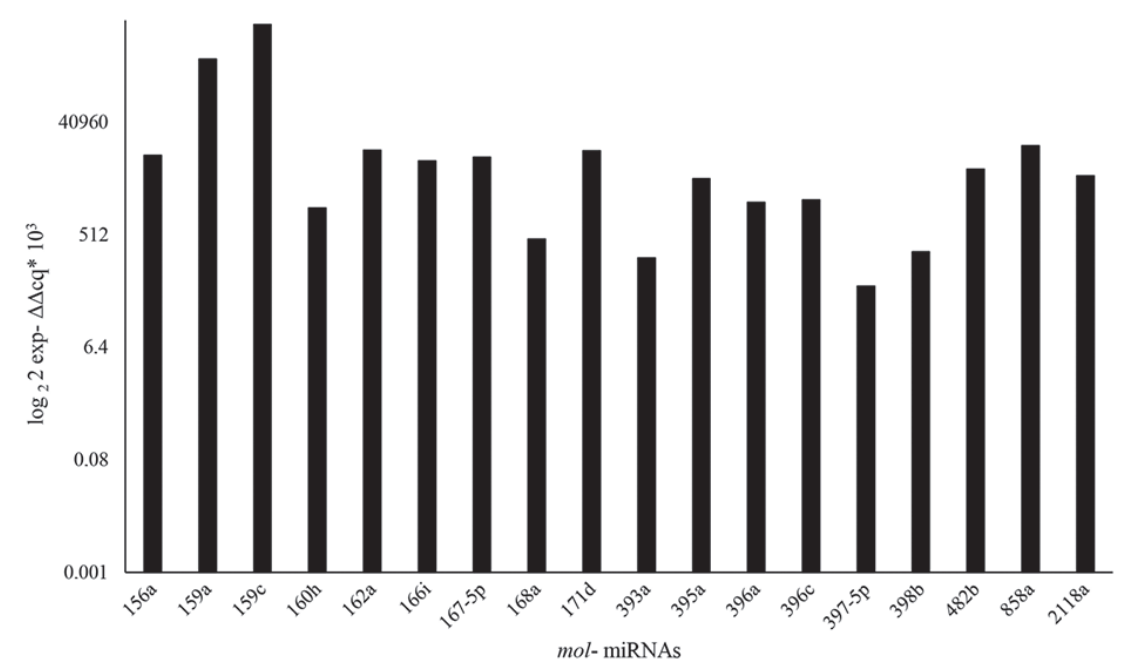

Figure 7. Characterization of microRNA from MOE-S. Relative RT-qPCR expression analysis of certain mol-miRNAs contained in the pool of small RNAs extracted from MOE-S. The analysis was carried out in three independent biological experiments and expressed as fold change with respect to mol-miR858b expression previously normalised with a housekeeping gene (5 S rRNA).

the biochemical profiles were similar between seeds and fresh seeds. In particular, L chromatograms appeared richer in peaks than seed chromatograms.

These results were confirmed by spectrophotometric measurements; indeed, all seed preparations seemed to be richer in total simple phenols than in flavonoids, with respect to leaves, in which flavonoids were more abundant compared to phenols. Several studies have demonstrated that the biological effects of MO may be associated with its secondary metabolites, such as flavonoids and simple phenols $(20,41,42)$.

Boiling, in general, seemed to be the best method to quantitatively and qualitatively extract the largest number of secondary metabolites from the plant material. In particular, leaves appeared to be the richest plant tissue in the plant compounds, confirming the results of a previous study (27) in which the authors demonstrated that the high concentration of metabolites in MO leaf preparations was able to induce cytotoxicity (28).

Zhang and other researchers demonstrated the cross-kingdom interaction concept, in which miRNA present in plant extracts introduced by the diet were able to control gene expression in human cells $(16,43,44)$. More recently, we have sequenced the miRnome of Moringa oleifera, and miRNA homologous to human miRNA was identified $(12,31)$. For this reason, in the present work, we have detected the presence of the most conserved plant microRNA, which could be the bioactive plant compounds involved in MO activity.

In conclusion, this paper described the effects of the African traditional preparation of MO seeds, highlighting its anti-proliferative and pro-apoptotic activities that may be responsible for the well-known curative properties of the plant known as the miracle tree. Moreover, we have demonstrated that small RNAs purified from Moringa oleifera seeds aqueous extract may be considered new important micronutrient elements.

Therefore, vegetal smallRNAs may be considered a new class of micronutrients responsible for the medical properties of plants and, the cross kingdom hypothesis may be though as a modern reinterpretation of the Hippocrates sentence 'Let food be thy medicine and medicine be thy food'.

\section{Acknowledgements}

Not applicable.

\section{Funding}

The present study was supported by the STARBIOS2 European Union's Horizon 2020 research and innovation programme under grant agreement No. 709517 oriented to promote Responsible Research and Innovation in biosciences.

\section{Availability of data and materials}

The materials used during the present study are available from the corresponding author on reasonable request.

\section{Authors' contributions}

CM, VC, AM and MP conceived and designed the present study. LC and AG performed HPLC analysis, and AG primarily identified and quantified the relevant vegetal small RNAs. AM, MP and VR performed cells treatment and Flow Cytometry analysis. FM analyzed the cytotoxic data. AM, MP and SG performed the ex vivo lymphocytes experiments. CM, AM, MP, AG, AC and VC critically assessed the results and wrote the paper. AM and MP contributed equally the experiments performed.

\section{Ethics approval and consent to particpate}

For the present study was obtained a written statement of 17 healthy donors consent to participate in the study as specified in the Declaration of Helsinki. The ethical approval for the collection and use of human samples was obtained in 2014, from ethical board of 'Tor Vergata' hospital, protocol number 15/14 (D.M.08.02.2013-D.G.R.146/2013; D.D.G.467 del 25.07.2013).

\section{Patient consent for publication}

Not applicable. 


\section{Competing interests}

The authors declare that they have no competing interests.

\section{References}

1. Padayachee B and Baijnath H: An overview of the medicinal importance of Moringaceae. J Med Plants Res 6: 5831-5839, 2012.

2. Goyal BR, Agrawal BB, Goyal RK and Mehta AA: Phyto-pharmacology of Moringa oleifera Lam?? an overview. Nat Prod Radiance 6: 347-353, 2007.

3. Ojewole JA: Antinociceptive, anti-inflammatory and antidiabetic properties of Hypoxis hemerocallidea Fisch. \& C.A. Mey. (Hypoxidaceae) corm ['African Potato'] aqueous extract in mice and rats. J Ethnopharmacol 103: 126-134, 2006.

4. Anwar F, Latif S, Ashraf M and Gilani AH: Moringa oleifera: A food plant with multiple medicinal uses. Phyther Res 21: 17-25, 2007

5. Almatrafi MM, Vergara-Jimenez M, Murillo AG, Norris GH, Blesso CN and Fernandez ML: Moringa leaves prevent hepatic lipid accumulation and inflammation in guinea pigs by reducing the expression of genes involved in lipid metabolism. Int J Mol Sci 18: pii: E1330, 2017

6. Stohs SJ and Hartman MJ: Review of the safety and efficacy of moringa oleifera. Phytother Res 29: 796-804, 2015.

7. Sagnia B, Fedeli D, Casetti R, Montesano C, Falcioni G and Colizzi V: Antioxidant and anti-inflammatory activities of extracts from Cassia alata, Eleusine indica, Eremomastax speciosa, carica papaya and Polyscias fulva medicinal plants collected in Cameroon. PLoS One 9: e103999, 2014.

8. Musumeci G, Maria Trovato F, Imbesi R and Castrogiovanni P: Effects of dietary extra-virgin olive oil on oxidative stress resulting from exhaustive exercise in rat skeletal muscle: A morphological study. Acta Histochem 116: 61-69, 2014.

9. Szychlinska MA, Castrogiovanni P, Trovato FM, Nsir H, Zarrouk M, Lo Furno D, Di Rosa M, Imbesi R and Musumeci G: Physical activity and Mediterranean diet based on olive tree phenolic compounds from two different geographical areas have protective effects on early osteoarthritis, muscle atrophy and hepatic steatosis. Eur J Nutr: Feb 15, 2018 (Epub ahead of print).

10. Estruch R, Ros E, Salas-Salvadó J, Covas MI, Corella D, Arós F, Gómez-Gracia E, Ruiz-Gutiérrez V, Fiol M, Lapetra J, et al: Primary prevention of cardiovascular disease with a Mediterranean diet. N Engl J Med 368: 1279-1290, 2013.

11. Gorzynik-Debicka M, Przychodzen P, Cappello F, Kuban-Jankowska A, Marino Gammazza A, Knap N, Wozniak M and Gorska-Ponikowska M: Potential health benefits of olive oil and plant polyphenols. Int J Mol Sci 19: pii: E686, 2018.

12. Minutolo A, Potestà M, Gismondi A, Pirrò S, Cirilli M Gattabria F, Galgani A, Sessa L, Mattei M, Canini A, et al: Olea europaea small RNA with functional homology to human miR34a in cross-kingdom interaction of anti-tumoral response. Sci Rep 8: 12413, 2018.

13. Lukasik A and Zielenkiewicz P: Plant MicroRNAs-novel players in natural medicine? Int J Mol Sci 18: pii: E9, 2016.

14. Zhou Z, Li X, Liu J, Dong L, Chen Q, Liu J, Kong H, Zhang Q, Qi X,Hou D, et al: Honeysuckle-encoded atypical microRNA2911 directly targets influenza A viruses. Cell Res 25: 39-49, 2015.

15. Liang G, Zhu Y, Sun B, Shao Y, Jing A, Wang J and Xiao Z: Assessing the survival of exogenous plant microRNA in mice. Food Sci Nutr 2: 380-388, 2014.

16. Zhang L, Hou D, Chen X, Li D, Zhu L, Zhang Y, Li J, Bian Z, Liang X, Cai X, et al: Exogenous plant MIR168a specifically targets mammalian LDLRAP1: Evidence of cross-kingdom regulation by microRNA. Cell Res 22: 107-126, 2012.

17. Sreelatha S, Jeyachitra A and Padma PR: Antiproliferation and induction of apoptosis by Moringa oleifera leaf extract on human cancer cells. Food Chem Toxicol 49: 1270-1275, 2011.

18. Jung IL: Soluble extract from Moringa oleifera leaves with a new anticancer activity. PLoS One 9: e95492, 2014.

19. Tiloke C, Phulukdaree A and Chuturgoon AA: The antiproliferative effect of Moringa oleifera crude aqueous leaf extract on cancerous human alveolar epithelial cells. BMC Complement Altern Med 13: 226, 2013.

20. Moyo B, Oyedemi S, Masika PJ and Muchenje V: Polyphenolic content and antioxidant properties of Moringa oleifera leaf extracts and enzymatic activity of liver from goats supplemented with Moringa oleifera leaves/sunflower seed cake. Meat Sci 91: 441-447, 2012.
21. Soladoye MO, Amusa NA, Raji-Esan SO, Chukwuma E and Taiwo AA: Ethnobotanical survey of anti-cancer plants in ogun state, nigeria. Ann Biol Res 1: 261-273, 2010.

22. Fuglie LJ: Combating malnutrition with Moringa. Engineering 3: 1999-2002, 2001

23. Mahmood KT, Mugal T and Haq IU: Moringa oleifera: A natural gift-a review. J Pharm Sci Res 2: 775-781, 2010.

24. Brenner D and Mak TW: Mitochondrial cell death effectors. Curr Opin Cell Biol 21: 871-877, 2009.

25. Li L, Yuan L, Luo J, Gao J, Guo J and Xie X:MiR-34a inhibits proliferation and migration of breast cancer through down-regulation of Bcl-2 and SIRT1. Clin Exp Med 13: 109-117, 2013.

26. Musumeci G, Castrogiovanni P, Loreto C, Castorina S, Pichler K and Weinberg AM: Post-traumatic caspase-3 expression in the adjacent areas of growth plate injury site: A morphological study. Int J Mol Sci 14: 15767-15784, 2013.

27. Gismondi A, Canuti L, Impei S, Di Marco G, Kenzo M, Colizzi V and Canini A: Antioxidant extracts of African medicinal plants induce cell cycle arrest and differentiation in B16F10 melanoma cells. Int J Oncol 43: 956-964, 2013.

28. Gismondi A, Reina G, Orlanducci S, Mizzoni F, Gay S, Terranova ML and Canini A: Nanodiamonds coupled with plant bioactive metabolites: A nanotech approach for cancer therapy. Biomaterials 38: 22-35, 2015

29. Bustin SA, Benes V, Garson JA, Hellemans J, Huggett J, Kubista M, Mueller R, Nolan T, Pfaffl MW, Shipley GL, et al: The MIQE guidelines: Minimum information for publication of quantitative real-time PCR experiments. Clin Chem 55: 611-622, 2009.

30. Gismondi A, Di Marco G and Canini A: Detection of plant microRNAs in honey. PLoS One 12: e0172981, 2017.

31. Pirrò $\mathrm{S}$, Minutolo A, Galgani $\mathrm{A}$, Potestà $\mathrm{M}$, Colizzi V and Montesano C: Bioinformatics prediction and experimental validation of MicroRNAs involved in cross-kingdom interaction. J Comput Biol 23: 976-989, 2016.

32. Pirrò S, Zanella L, Kenzo M, Montesano C, Minutolo A, Potestà M, Sobze MS, Canini A, Cirilli M, Muleo R, et al: MicroRNA from Moringa oleifera: Identification by high throughput sequencing and their potential contribution to plant medicinal value. PLoS One 11: e0149495, 2016.

33. Xia R, Zhu H, An QY, Beers EP and Liu Z: Apple miRNAs and tasiRNAs with novel regulatory networks. Genome Biol 13: R47, 2012.

34. Zhang BH, Pan XP, Wang QL, Cobb GP and Anderson TA: Identification and characterization of new plant microRNAs using EST analysis. Cell Res 15: 336-360, 2005.

35. Saini RK, Sivanesan I and Keum YS: Phytochemicals of Moringa oleifera: A review of their nutritional, therapeutic and industrial significance. 3 Biotech 6: 203, 2016.

36. Razis AFA, Ibrahim MD and Kntayya SB: Health benefits of Moringa oleifera. Asian Pac J Cancer Prev 15: 8571-8576, 2014.

37. Kou X, Li B, Olayanju JB, Drake JM and Chen N: Nutraceutical or pharmacological potential of Moringa oleifera lam. Nutrients 10: pii: E343, 2018.

38. Karim NA, Ibrahim MD, Kntayya SB, Rukayadi Y, Hamid HA and Razis AF: Moringa oleifera Lam: Targeting chemoprevention. Asian Pacific J Cancer Prev 17: 3675-3686, 2016.

39. Suphachai C: Antioxidant and anticancer activities of Moringa oleifera leaves. J Med Plants Res 8: 318-325, 2014.

40. Sasidharan S, Chen Y, Saravanan D, Sundram KM and Yoga Latha L: Extraction, isolation and characterization of bioactive compounds from plants' extracts. Afr J Tradit Complement Altern Med 8: 1-10, 2011

41. Fard MT, Arulselvan P, Karthivashan G, Adam SK and Fakurazi S: Bioactive extract from moringa oleifera inhibits the pro-inflammatory mediators in lipopolysaccharide stimulated macrophages. Pharmacogn Mag 11 (Suppl 4): S556-S563, 2015.

42. Coppin JP, Xu Y, Chen H, Pan MH, Ho CT, Juliani R, Simon JE and $\mathrm{Wu}$ Q: Determination of flavonoids by LC/MS and anti-inflammatory activity in Moringa oleifera. J Funct Foods 5: 1892-1899, 2013.

43. Hou D, He F, Ma L, Cao M, Zhou Z, Wei Z, Xue Y, Sang X, Chong H, Tian C, et al: The potential atheroprotective role of plant MIR156a as a repressor of monocyte recruitment on inflamed human endothelial cells. J Nutr Biochem 57: 197-205, 2018.

44. Chin AR, Fong MY, Somlo G, Wu J, Swiderski P, Wu X and Wang SE: Cross-kingdom inhibition of breast cancer growth by plant miR159. Cell Res 26: 217-228, 2016.

This work is licensed under a Creative Commons Attribution-NonCommercial-NoDerivatives 4.0 International (CC BY-NC-ND 4.0) License. 